\title{
LOW PRESSURE WARNING SYSTEM WITH AUTOMATIC TRANSFER
}

\author{
E. James Theloar, m.D., and Roy Connell
}

C. S. WARD ${ }^{1}$ has described previous devices used to indicate failure of oxygen supply. These include the "bosun" warning device, the Wantage oxygen failure alarm, ${ }^{2}$ the Coote warning device, ${ }^{3}$ the Adler and Burn device, ${ }^{4}$ the "fail safe" oxygen device, ${ }^{5}$ and the ECG gas failure alarm. ${ }^{6}$ The reader is referred to Ward's paper for descriptions. It is evident from the above list that a warning system of oxygen failure is a desirable item. Every anaesthesiologist at some time has felt concerned with regard to his gas supply, and no doubt avoidable death has occurred because of oxygen failure. Ward's article makes the following points with regard to warning devices.

1. The use of a warning device should be regarded as a valuable precaution which is desirable but not essential. It does not excuse the anaesthesiologist from the responsibility of constant vigilance.

2. The warning system should be operated by and dependent upon the pressure of oxygen in the supply line.

3. It should be rigorously tested before it is brought into use.

4. It should not be dependent upon the electrical supply, on batteries, or on the pressure of nitrous oxide.

5. The warning system should operate on the "reduced" side of the oxygen supply line and should be additional to the existing contents gauge, which would remain proximal to the reducing valve.

It is felt that the mechanism to be described fulfils the requirements listed above. Emphasis must again be placed on the responsibility of the anaesthesiologist for continuous vigilance, and this attachment, while fulfilling the requirements of suitability, must not decrease this care and watchfulness. As noted by A. Murray Wilson, ${ }^{6}$ gadgets such as described here can only be an adjunct to continuous observation while aiding peace of mind at complex moments. However, there is an added advantage inasmuch as it enables the oxygen tanks to be emptied completely, with consequent saving.

Since development of our low pressure warning system and automatic transfer we have studied the oxygen warning device recently developed by C. S. Ward. ${ }^{7}$ While probably similar in principle to his, it is felt that the mechanism to be described in this paper (Fig. 1) offers some advantages. Among these are the following:

1. A gearing device allows for variable low pressures from 20 to $60 \mathrm{psi}$; i.e. it has rangeability of adjustment.

2. Only one whistle is required for the system, covering the full range of pressures.

3. The fact that the alarm and transfer settings are related through a gear ratio 


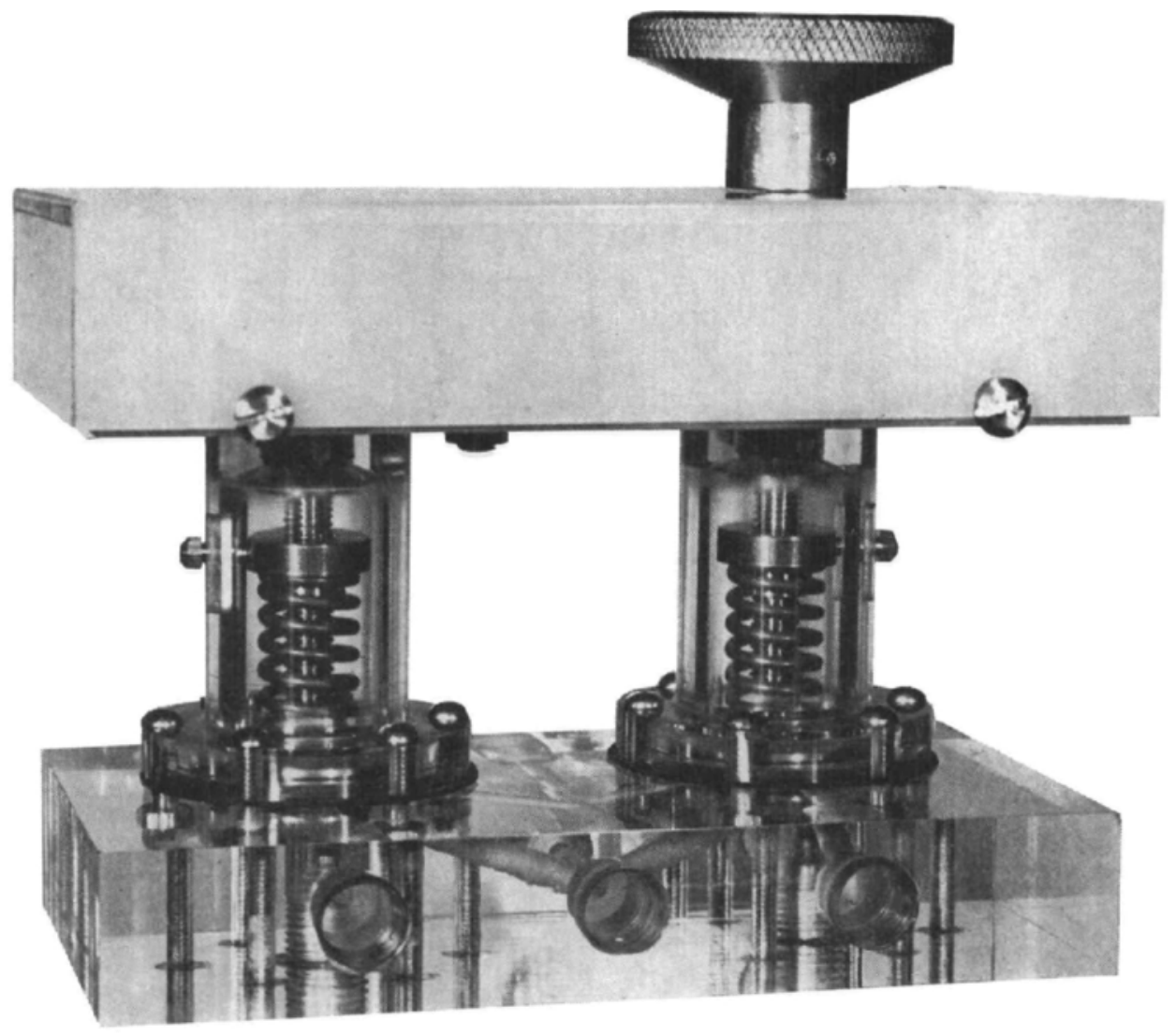

Figure 1. The "Alert Mark vir” low pressure warning device.

means that the transfer setting cannot inadvertently be set above the alarm setting.

Epstein $^{8}$ in his paper entitled "The Prevention of Accidental Breathing of Anoxic Gas Mixtures during Anesthesia" lists the following hazards:

1. Exhaustion of the oxygen cylinder.

2. Insufficient opening of the oxygen cylinder to permit a free flow of gas after the pressure falls.

3. Failure of gas pressure in a piped oxygen system.

4. Failure to open the valve of a piped oxygen system (this may not be recognized because of the flow of gas from a cylinder source which is subsequently closed).

5. Non-positive lock between oxygen piping and gas machine.

6. Failures in reducing valve or gas manifold.

7. Inadvertent disturbance of the setting of the oxygen flowmeter.

We feel that this warning system prevents all of the above hazards with the exception of numbers 5 and 7 . 


\section{Description}

Our system employs two pneumatic switches, one from the "main" supply tank and one from the "auxiliary" supply tank (Fig. 2). Because of the gearing mechanism as noted above, it is impossible to set valve $\mathbf{B}$ higher than valve $\mathbf{A}$. They are set 10 psi apart for use with the bank tanks.

A typical system operates as follows: the alarm and transfer settings are $10 \mathrm{psi}$ apart as indicated on the dial of the device. They might be set, for example, at 40 and $30 \mathrm{psi}$, the difference between the two being regulated automatically by the gearing device. The regulator governing the line pressure from the main tank should be set 10 psi above the alarm setting - in this case at 50 psi. The regulator on the auxiliary tank should be set at 50 psi as well, since this is the pressure for which the alarm and transfer settings are calibrated.

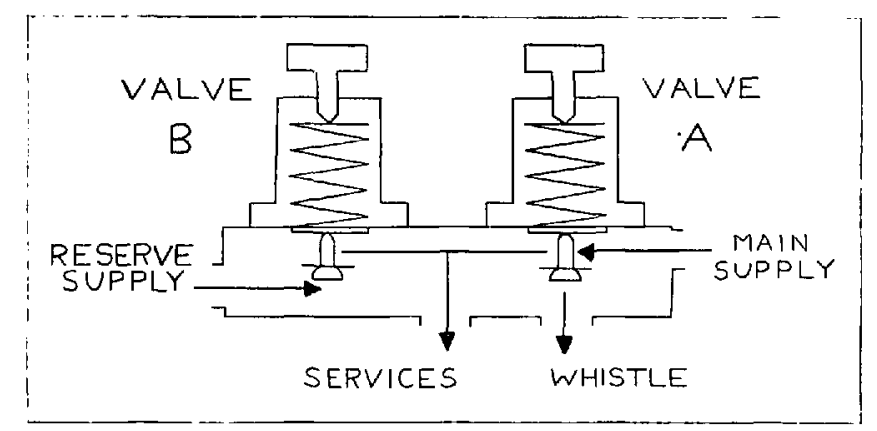

Figure 2. Schematic drawing of the low pressure warning device.

Under normal conditions, while the main supply tank is in use, with the pressure regulator set at 10 psi above the alarm setting, both valves $\mathbf{A}$ and $\mathbf{B}$ are closed. When the main supply tank begins to empty, the pressure falls, and when it reaches the alarm setting which is variable between 20 and 60 psi, valve $\mathrm{A}$ opens and the whistle sounds. The pressure continues to fall until the transfer setting is reached, whereupon valve B opens. The output line is then supplied with gas from the auxiliary tank and the alarm continues to sound until a fresh tank with sufficient pressure to reach 10 psi above the alarm setting is connected. This can be conveniently done by a $\mathrm{Y}$ or $\mathrm{T}$ piece. As soon as this tank is opened both valves close and the system is once again operating under normal conditions. It is, therefore, a three-tank system. A fresh tank of oxygen should be ordered and the empty cylinder replaced as soon as possible after the whistle blows. Should there not be a tank available because of oversight, the whistle can only be overcome by switching off the auxiliary supply and reverting to the small gas tanks on the anaesthetic machine.

\section{Method of Setting Up}

At the start of each day or period of use, the anaesthetic machine is first connected to the wall in the routine manner and the gas turned on via the 


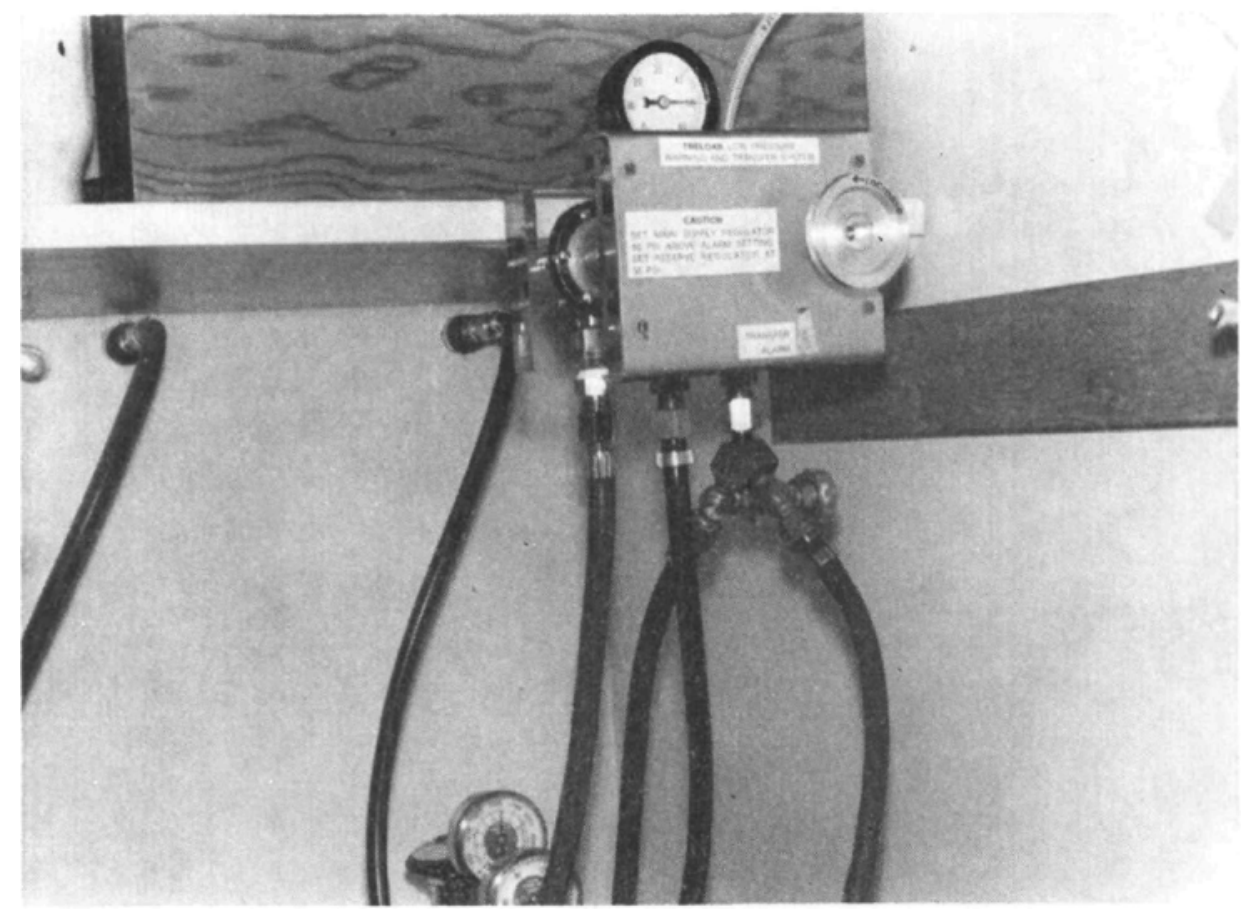

Figure 3. Low pressure waming system with automatic transfer, shown in position.

rotameter or flush valve. The auxiliary tank is then opened and the regulator adjusted to 50 psi. During this time the whistle will sound and this serves as a confirmation of its functioning. The oxygen tank in use on the main supply is then opened and the whistle will stop when the regulator is adjusted so that the line pressure is 10 psi above the alarm setting. The gas flow is then shut off at the anaesthetic machine and the system is ready for use. When it is not in use, all tanks should be turned off.

\section{SUMMARY}

This article describes a mechanism which will give a mechanical warning of mainline gas pressure failure and at the same time automatically turn on a fresh gas supply. The device is designed for operation where large tanks are in use. Modifications have been made and trials carried out for use with anaesthetic machines.

\section{RÉSUMÉ}

Cet article décrit un dispositif qui donne un avertissement mécanique d'une baisse de pression dans l'entrés principale de gaz et en même temps se raccorde automatiquement à une source de gaz sous pression normale. Cette invention est destinée à ceux qui se servent de gros réservoirs. On a apporté des modifications et on a fait des expériences pour utiliser ce dispositif avec les appareils à anesthésie. 


\section{ACKNOWLEDGMENTS}

We wish to thank R. E. Simpson, M.D. and P. W. Klassen, M.D. for their cooperation and assistance in developing this device. We are grateful to Dr. Paul Rondeau and Dr. E. Yeung and staff for their co-operation during the trials of this mechanism.

\section{REFERENCES}

1. WAFD, C. S. The Prevention of Accidents Associated with Anaesthetic Apparatus. Brit. J. Anaesth. 40: 692 (1968).

2. Cooke, Michael \& Waine, Theodore E. Warning Device Connected Directly to the Oxygen Cylinder. Anaesthesia. 22: 487 (1967).

3. HILL, E. F. Another Warning Device. Brit. J. Anaesth. 28 : 226 (1956).

4. Adler, Lawrence \& Burn, N. Warning Device for Failure of the Oxygen Supply. Anaesthesia. 22: 156 (1967).

5. LuCAs, B. C. B. \& Fisher, A. L. A "Fail Safe" Oxygen Device. Brit. Med. J. 1: 551

6. Wilson, A. Murray. Warning Devices on Anaesthetic Apparatus. Anaesthesia. 20: 403 (1965).

7. WARD, C. S. Oxygen Warning Device. Brit. J. Anaesth. 40: 907 (1968).

8. Epstein, R. M.; Rockow, Hermert; Arnold, Lee St. J.; \& Papper, E. M. Prevention of Accidental Breathing of Anoxic Gas Mixtures during Anesthesia. Anesthesiology. 23: 1 (1962). 